\title{
FLAVIA NORONHA RODRIGUES
}

\section{O descarte de próteses de PVC atóxico}

\section{MONOGRAFIA}

Monografia apresentada ao Programa de Pós Graduação em Educação da PUC-Rio como quesito parcial para obtenção do título de Especialista em Educação Ambiental.

Orientadora: Solange de Almeida Cardozo 


\section{Flavia Noronha Rodrigues}

\section{O descarte de próteses de PVC atóxico}

\section{MONOGRAFIA}

Monografia apresentada ao Programa de Pós Graduação em Educação da PUC-Rio como que sito parcial para obtenção do título de Especialista em Educação Ambiental. Aprovada pela Comissão Examinadora Abaixo Assinada

Orientadora:

Prof. Solange de Almeida Cardozo.

Coordenação de Extensão CCE/ PUC-RIO

Avaliadora:

Prof. Hedy Silva Ramos de Vasconcellos

Departamento de Educação/ PUC-Rio 


\section{Agradecimentos}

São muitas as pessoas a quem desejo agradecer por ter chegado ao final deste curso com sucesso, não tenho dúvidas de que cada um dedicou a mim o que tinha de melhor.

Aos meus pais pelo eterno incentivo aos estudos que fizeram de mim o que sou hoje e me trouxeram até aqui com um amor tão grande que é impossível descrever ou retribuir.

Ao meu amor Vinicius que me apoiou mesmo nos momentos mais difíceis, compreendeu todo meu estresse e me auxiliou para que minhas ideias pudessem se transformar em palavras.

Aos colegas de turma que se transformaram em queridos(as) amigos(as). Que me deram suporte para encarar essa monografia, me animaram todas as terças e quintas para encarar depois do trabalho o combo transito mais aulas. Pessoas com quem troquei muitas experiências e tanto aprendi sobre a vida.

Aos(às) bons(as) professores(as) que passaram por minha vida me presenteando com conhecimentos e despertando o desejo de aprender cada vez mais.

À querida Professora Hedy (Dra. Hedy Silva Ramos de Vasconcellos), uma educadora incansável, pessoa que tenho como exemplo de amor, luta e dedicação à profissão.

E, finalmente, à minha orientadora, Professora Solange Cardozo que é maravilhosa e abraçou a minha ideia, sem a força e animação dela não teria concluído essa etapa do curso.

Muito obrigada a todos! 


\section{Resumo}

O que é feito com todo resíduo sólido gerado pelas próteses feitas de plástico policloreto de polivinila mais conhecido pelo acrônimo PVC, que é um plástico não 100\% originário do petróleo)? Esta questão é o foco da pesquisa.

As abordagens integradas sobre saúde e ambiente são muito recentes, datando do final dos anos 70 do século XX, quando tanto ambientalistas quanto sanitaristas, tanto investigadores quanto gestores, começaram a perceber a necessidade de articular mais suas teorias e suas ações com a ideia da qualidade de vida de populações concretas. Esse propósito, de um lado, veio da convicção de que não pode haver desenvolvimento sustentável sem levar em conta os seres humanos e sua vida no ecossistema. Sob essa perspectiva, o objetivo de minha pesquisa foi buscar informações junto aos fabricantes, lojistas e consumidores como é feito o descarte das próteses feitas de PVC atóxico e poder com essa pesquisa auxiliar na conscientização das pessoas em relação ao meio ambiente e à sociedade em que estão inseridas. Doar as próteses é praticamente impossível, além de ser um objeto pessoal que gira em torno de um tabu. É um material usado e contaminado e por isso as próteses eletrônicas ou são esquecidas em alguma gaveta ou são descartadas em lixo comum. Mesmo sendo possível reciclar toda parte eletrônica do produto no Brasil isso não acontece. Os entrevistados sinalizaram que nunca tinham pensado sobre o assunto de forma sócio ambiental e em todos os problemas que o descarte inadequado desse material pode acarretar.

\section{Palavras chave}

Educação Ambiental, Resíduo Sólido Urbano, Descarte Consciente, Meio Ambiente e Saúde. 


\section{Sumário}

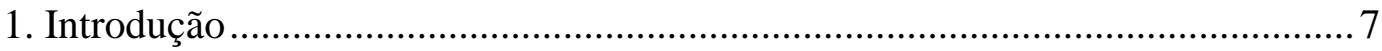

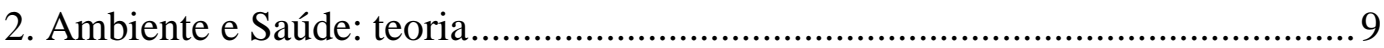

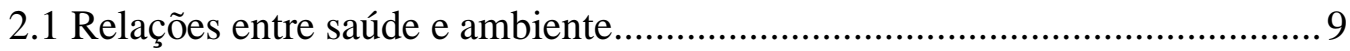

2.2 Breve histórico da questão ambiental ...................................................... 10

2.3 Política Nacional de Resíduos Sólidos (PNRS) ............................................ 12

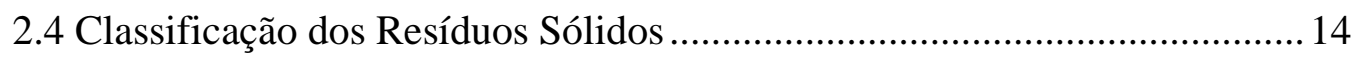

2.5 Acondicionamento dos Resíduos Sólidos .................................................... 15

2.6 Tratamento e Disposição Final dos Resíduos Sólidos .................................. 16

2.7 Efeitos na saúde humana e no meio ambiente .......................................... 18

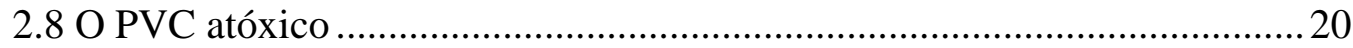

3. Ambiente e Saúde: os achados da pesquisa .................................................... 23

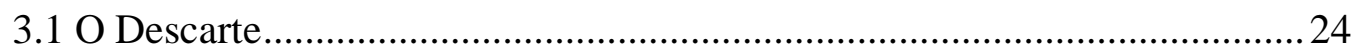

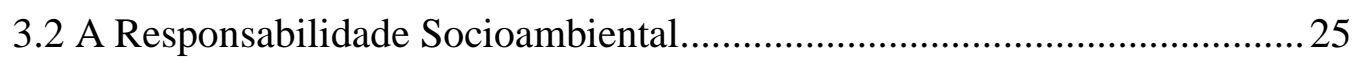

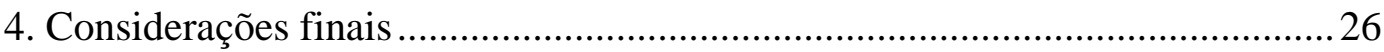

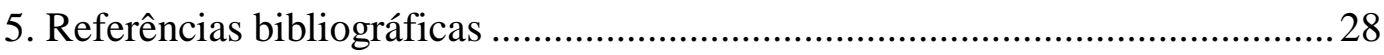




\section{Lista de siglas}

ABNT - Associação Brasileira de Normas Técnicas

AIDS - Síndrome da Imuno Deficiência Adquirida

DST - Doença Sexualmente Transmissível

IBGE - Instituto Brasileiro de Geografia e Estatística

NBR - Norma Brasileira

OMS - Organização Mundial de Saúde

PNRS - Política Nacional de Resíduos Sólidos

PRONAR - Programa Nacional de Reciclagem

PVC - Policloreto de polivinila (ou policloreto de vinil)

UNCED ((sigla em inglês) United Nations Commission on Environment and Development) - Conferência das Nações Unidas sobre o Meio Ambiente e Desenvolvimento.

\section{Lista de tabelas}

Tabela 1 - Composição média do lixo domiciliar. .14 


\section{1. \\ Introdução}

Minha formação familiar contribuiu de certa forma para a escolha do meu curso, minha mãe é do interior do Estado do Rio de Janeiro criada em uma fazenda. Saiu da sua cidade para ganhar o mundo, estudou se formou em Pedagogia, mas nunca esqueceu as raízes. Meu pai é agrônomo de formação e amante da terra de coração. Meu crescimento foi em contato direto com a natureza e sempre foi me ensinado a respeitá-la, o que me fez querer ser Bióloga.

Após alguns anos trabalhando na área e com avaliação de ensino, me vi em um emprego que não me fazia mais feliz, fazendo um trabalho que eu não concordava.

Resolvi começar o curso de Pós-graduação em Educação Ambiental na PUC -RJ que me trouxe uma visão mais interdisciplinar do mundo, levando em consideração as parte não só ambiental como também a econômica social e cultural.

Foi quando surgiu uma proposta de dois amigos meus da época de colégio para trabalhar com eles em um novo negócio. Foi assim que eu aceitei e fui trabalhar fora da minha área na Sexdesejo, um site de vendas de produtos eróticos.

Biologia não é somente uma profissão. Acaba virando parte da vida, de um estilo de vida, parte de você. E foi no meio de tantos produtos de borracha, embalagens plásticas materiais defeituosos que eu encontrei a minha inquietação e assim o tema da minha monografia.

O que é feito com todo resíduo solido gerado principalmente as próteses feitas de plástico PVC, que é um plástico não $100 \%$ originário do petróleo, você sabe? Esta questão intrigou-me e tornei-a o foco de minha pesquisa.

Todo debate sobre saúde e ambiente parte de dois pressupostos básicos: o primeiro é a essencialidade da relação entre os seres humanos e a natureza. O segundo, derivado dessa relação, é o de que o conceito de ambiente, tal como o entendemos, é construído pela ação humana. Dessa forma ele é histórico e pode 
ser pensado, repensado, criado e recriado, tendo em vista nossa responsabilidade presente e futura com a existência, as condições e a qualidade da vida dos indivíduos em sociedade e de toda a biosfera. (Minayo, 1998).

As abordagens integradas sobre saúde e ambiente são muito recentes, datando do final dos anos 70 do século $\mathrm{XX}$, quando tanto ambientalistas quanto sanitaristas, tanto investigadores quanto gestores, começaram a perceber a necessidade de articular mais suas teorias e suas ações com a ideia da qualidade de vida de populações concretas. Esse propósito, de um lado, veio da convicção de que não pode haver desenvolvimento sustentável sem levar em conta os seres humanos e sua vida no ecossistema.

Portanto, se queremos compreender o impacto da atividade humana sobre o ambiente e, por sua vez, a força desse impacto na saúde humana, é necessário criar estratégias específicas que, a partir de conhecimentos disciplinares e práticas setoriais, caminhem para uma abordagem transdisciplinar.

Sob essa perspectiva, o objetivo de minha pesquisa foi buscar informações junto aos fabricantes, lojistas e consumidores como é feito o descarte das próteses feitas de PVC atóxico e poder com essa pesquisa auxiliar na conscientização das pessoas em relação ao meio ambiente e à sociedade em que estão inseridas.

São objetivos específicos:

- Descarte correto do lixo produzido visando a não geração, redução, reutilização, reciclagem, tratamento dos resíduos e evitando que o mesmo seja descartado de forma incorreta;

- Relacionar os resíduos espalhados com problemas ambientais e de saúde;

- Conhecer os mecanismos oficiais de coleta de resíduos sólidos;

- Criar uma consciência ambiental sobre o lixo que produzimos ser de nossa responsabilidade.

Este estudo foi realizado no período de Janeiro de 2016 a Dezembro de 2016 com os dois fabricantes de próteses de material PVC no Rio Grande do Sul e em São Paulo, com três lojistas do Rio de Janeiro e um de Minas Gerais e também 
com vinte consumidores assíduos desse tipo de produto, dentre eles casais, mulheres e homens entre 24 a 68 anos.

O capitulo dois (2) traz os conceitos e as inter relações entre saúde e ambiente. Inicialmente foi feita uma breve retomada de conceitos de Educação Ambiental caracterizando sua importância. Em seguida, foi necessário tratar o tema Resíduos Sólidos. Questão de fundo da pesquisa. Seus conceitos, leis, dados quantitativos.

O capítulo três (3) traz os achados da pesquisa.

Finalmente, o capitulo quatro apresenta, como seu título indica, as “Considerações finais" sobre a pesquisa. 


\section{2. \\ Ambiente e Saúde: teoria}

\section{1}

\section{Relações entre saúde e ambiente}

Com base em Leff (2001) a Educação Ambiental é definida como um processo no qual se incorporam critérios socioambientais, ecológicos, éticos estéticos nos objetivos didáticos da educação, como propósito de construir novas formas de pensar, incluindo uma melhor compreensão da complexidade, das emergências e das inter-relações entre os diversos subsistemas que compõem a realidade. O ponto central desse enfoque é que a preservação/recuperação do ambiente é algo que atinge a todos.

Para Frigotto (2001),

\footnotetext{
"A educação supõe sempre mudança, a mente aberta para o mundo, recebendo as influências deste mundo, em diversos aspectos. Este movimento promove a relação dos elementos que aí estão: objetos, pessoas, ideias, teorias pedagógicas"!
}

Os fatores ambientais afetam dramaticamente a saúde de muita gente no mundo. A Organização Mundial de Saúde (OMS) estima que cerca de três milhões de crianças morrem anualmente por causas relacionadas a problemas de água e de contaminação e mais de um milhão de adultos morrem por causas relacionadas ao trabalho. Cerca de $80 \%$ a $90 \%$ dos casos de diarreia são causados por fatores ambientais. Entre 2 a 3 e meio bilhões de pessoas no mundo usam combustíveis que emitem gases e outras substâncias nocivas. E nas áreas rurais, técnicas rudimentares de criação de animais são responsáveis por enfermidades transmissíveis, muitas vezes pondo em risco, elevadas proporções da população mundial, tendo em vista os efeitos das intensas ondas de migração, turismo e comunicação (Lebel, 2005).

A educação para a cidadania requer que as questões sociais sejam apresentadas para a aprendizagem e reflexão dos alunos, buscando-se um tratamento didático que contemple a complexidade e dinâmica dessas questões, dando-lhes a mesma importância que nas áreas convencionais de ensinoaprendizagem. Com isso o currículo ganha em flexibilidade e abertura, uma vez que os temas podem ser priorizados e contextualizados de acordo com as 
diferentes realidades locais e regionais, já que novos temas podem sempre ser incluídos (Brasil, 1987).

Embora não existam dúvidas sobre a importância da atividade de limpeza urbana para o meio ambiente e para a saúde da comunidade, esta percepção não se tem traduzido em ações efetivas que possibilitem mudanças qualitativas na situação negativa em que se encontram, de forma geral, os sistemas de gerenciamento de resíduos sólidos urbanos em toda a América Latina, inclusive no Brasil.

Os efeitos adversos dos resíduos sólidos municipais no meio ambiente, na saúde coletiva e na saúde do indivíduo são reconhecidos por diversos autores (Accurio et al., 1998; Anjos et al., 1995; Cantanhede, 1997; Diaz et al., 1997; Ferreira, 1997; Leite \& Lopes, 2000; Maglio, 2000; Robazzi et al., 1992; Velloso, 1995; Zepeda, 1995), que apontam as deficiências nos sistemas de coleta e disposição final e a ausência de uma política de proteção à saúde do trabalhador, como os principais fatores geradores desses efeitos.

Nos últimos trinta anos vários enfoques têm sido propostos para o entendimento das complexas relações entre saúde e ambiente. A visão complexa que reconhece a saúde como, um bem social, levanta também a necessidade do investimento em novas abordagens integradas em ciência e tecnologia, na construção coletiva da cultura e na responsabilização social. Esse propósito, de um lado, veio da convicção de que não pode haver desenvolvimento sustentável sem levar em conta os seres humanos e sua vida no ecossistema.

\section{2}

\section{Breve histórico da questão ambiental}

O tema ambiental surgiu pela primeira vez na Agenda Mundial em 1972 na Conferência das Nações Unidas sobre o ambiente, em Estocolmo, coincidindo com a crise do petróleo que chamou atenção dos países industrializados para a problemática dos recursos naturais não renováveis. Da reunião de Estocolmo nasceu a expressão eco desenvolvimento. Já o esforço de formular propostas concretas que visassem a estreitar a relação entre saúde e ambiente se evidenciou na preparação da Rio-92. 
Um dos documentos preparatórios, o Relatório da Comissão Mundial sobre meio Ambiente e Desenvolvimento (1991) denominado Nosso Futuro Comum, apresentou o conceito de desenvolvimento sustentável como o que satisfaz as necessidades do presente sem prejudicar ou comprometer a capacidade das gerações vindouras de conseguirem satisfazer suas necessidades. Esse documento identificou o papel dos seres humanos em relação ao ambiente e descreveu o impacto das mudanças ambientais sobre a saúde e qualidade de vida das populações. A partir da Rio-92, o relatório da Conferência das Nações Unidas sobre o Meio Ambiente e Desenvolvimento (UNCED (sigla em inglês) - United Nations Commission on Environment and Development) propôs a Agenda 21, termo usado para designar um plano de ação para o desenvolvimento sustentável (UNCED, 1992).

A Agenda 21 teve como signatários 178 chefes de Estado e de governo e configurou-se como um pacto internacional a partir de recomendações que objetivaram criar um processo para a substituição negociada do padrão de desenvolvimento predatório, predominante no século XX. Nela foi estabelecida claramente a estreita relação entre saúde e ambiente. Um capítulo inteiro da Agenda está dedicado à proteção e à promoção da saúde humana.

A Agenda destacou a conexão entre pobreza e subdesenvolvimento, por um lado, entre a proteção do ambiente e os recursos naturais.

O documento da UNCED ressaltou que, no mundo em geral, mais especialmente nos países subdesenvolvidos se unem, a favor da precarização da saúde, vários e combinados fatores. Dentre esses se destacam: falta de saneamento básico; água e alimentos de baixa qualidade; poluição do ar; uso desordenado de produtos químicos; manejo inapropriado do lixo; exposição a vetores e a doenças; condições insalubres de moradia.

Em 2002 aconteceu a Cúpula Mundial sobre Desenvolvimento Sustentável em Johanesburgo (África do Sul), comemorando dez anos da Rio-92. Nesse evento as ênfases foram dadas aos aspectos sociais e econômicos do desenvolvimento sustentável. A saúde foi uma das cinco prioridades. A Organização Mundial da Saúde assumiu a responsabilidade por um plano de ação 
sobre saúde e ambiente, no qual os dois temas se cruzam para tratar problemas como manejo de substâncias tóxicas e contaminação do ar, da água e do solo (Lebel, 2005).

\section{3}

\section{Política Nacional de Resíduos Sólidos (PNRS)}

O projeto de PNRS, após 19 anos de tramitação, foi aprovado no dia 10 de março de 2010 pela Câmara dos Deputados, porém no dia 2 de agosto de 2010 sob a lei 12.305 é instituída a PNRS, na qual surgiu com novas providências alterando a lei 9.605/98 (Souza, 2012, p76).

O Brasil passa a ter um marco regulatório na área de Resíduos Sólidos. A lei faz a distinção entre resíduos (lixo que pode ser reaproveitado ou reciclado) e rejeito (o que não é passível de reaproveitamento). A lei se refere a todo tipo de resíduos (Souza, 2012, p.76).

A PNRS reúne princípios, objetivos, instrumentos e diretrizes para a gestão dos resíduos sólidos. É fruto de ampla discussão com os órgãos de governo, instituições privadas, organizações não governamentais e sociedade civil (Schramm, 2009, p.26).

A lei tem como objetivo a não geração, redução, reutilização e tratamento de resíduos sólidos, bem como a destinação final ambientalmente adequada dos rejeitos. Redução do uso dos recursos naturais (água e energia, por exemplo) no processo de produção de novos produtos, intensificar ações. de educação ambiental, aumentar a reciclagem no país, promover a inclusão social, a geração de emprego e renda de catadores de materiais recicláveis (Scramm, 2009, p.26).

Segundo a normativa da ABNT NBR 10004/1987 apud Barros (2003), os resíduos sólidos são definidos como:

\footnotetext{
"resíduos nos estados sólido e semi sólido, que resultam de atividades da comunidade de origem: industrial, doméstica, hospitalar, comercial, agrícola, de serviços e de varrição. Ficam incluídos nesta definição os lodos provenientes de sistemas de tratamento de água, aqueles gerados em equipamentos e instalações de controle de poluição, bem como determinados líquidos cujas particularidades tornem inviável o seu lançamento na rede pública de esgotos ou corpos d'água, ou exijam para isso soluções técnicas e economicamente inviáveis em face à melhor tecnologia disponível".
} 
Após a Revolução Industrial, a urbanização se intensificou em todo o planeta, a ponto de ser considerada por alguns cientistas como a transformação social mais importante de nosso tempo. (Figueiredo, 1994). Em países subdesenvolvidos como o Brasil o processo de urbanização surgiu acompanhado por uma decadência nos padrões de vida, resultado de um êxodo rural onde as oportunidades de emprego e de melhores condições de vida pareciam estar nos centros urbanos.

O exame do processo de urbanização pelo qual o Brasil atravessa é importante, tanto para a percepção da dinâmica dos resíduos urbanos, quanto para a representação dos prováveis e/ou possíveis quadros, com os quais nos encontraremos futuramente, relativos à questão (Figueiredo, 1994). Foram apenas no decorrer dos últimos 20 anos que se iniciaram no Brasil os programas de reciclagem e coletas seletivas que visam à diminuição da quantidade de "lixo" nos municípios.

Atualmente, um dos problemas mais sérios enfrentados pela comunidade é o lixo urbano. Esse problema se relaciona diretamente com o crescimento constante da população, exigindo mais produção de alimentos e industrialização de matérias-primas, transformando-as em produtos industrializados, contribuindo, assim, para o aumento dos resíduos sólidos, com consequências desastrosas para o meio ambiente e para a qualidade de vida da coletividade (Fonseca, 1999).

De acordo com o Instituto Brasileiro de Geografia e Estatística (IBGE, 2005), 76\% dos resíduos sólidos residenciais, em cidades brasileiras, não tem recebido tratamento adequado, podendo ser facilmente observados em acúmulos nas ruas, terrenos baldios, leitos de rios, valas, encosta de morros e outros locais impróprios, prejudicando a população local, os moradores da cidade em geral e, o próprio espaço habitado, com a produção e liberação de produtos.

Nesse contexto, existem vários sistemas de disposição final de resíduos sólidos como descarga a céu aberto ou lixão; aterro controlado (lixão controlado); aterro sanitário e aterro sanitário energético; compostagem; reciclagem e; incineração. Esses processos são utilizados no Brasil, onde são geradas 
diariamente cerca de 240.000 toneladas de resíduos sólidos, somente em áreas urbanas. E destes, aproximadamente 90.000 toneladas/dia (32 milhões de toneladas por ano), são de resíduos sólidos domésticos (Atyel, 2001).

Por intermédio do Programa Nacional de Reciclagem (PRONAR), uma iniciativa do governo que não saiu do papel, se iniciou o interesse pelas vantagens que poderiam advir do lixo (Franco, 2000).

\begin{abstract}
"De fato, os resíduos se transformaram em graves problemas urbanos e ambientais com um gerenciamento oneroso e complexo. A escassez de área de deposição de resíduos causada pela ocupação e valorização de áreas urbanas, os altos custos sociais no gerenciamento de resíduos, problemas de saneamento público e contaminação ambiental são alguns destes problemas." (John, 2000)."
\end{abstract}

De acordo com Galvão Jr. (1994), a composição média do lixo domiciliar brasileiro é a seguinte:

Tabela 1 - Composição Média do Lixo Domiciliar

\begin{tabular}{|l|l|}
\multicolumn{1}{|c|}{ Componentes } & \multicolumn{1}{c|}{ Percentual (em peso) } \\
Matéria orgânica & $52,5 \%$ \\
Papel e papelão & $24,5 \%$ \\
\hline Plástico & $2,9 \%$ \\
\hline Metal Ferroso & $1,4 \%$ \\
Metal não Ferroso & $0,9 \%$ \\
\hline Vidro & $1,6 \%$ \\
\hline Outros & $16,2 \%$ \\
\hline \multicolumn{2}{c}{ TOTAL } \\
\hline
\end{tabular}

Fonte: Galvão Jr. (1994)

\title{
2.4
}

\section{Classificação dos Resíduos Sólidos}

A normativa 10004 de 1987 da ABNT, classifica os resíduos sólidos e os organiza em classes, podendo ser:

CLASSE I - perigosos: são aqueles que, em função de suas propriedades físicas, químicas ou infecto-contagiosas, podem apresentar riscos à saúde pública 
ou ao meio ambiente, ou ainda os inflamáveis, corrosivos, reativos, tóxicos ou patogênicos;

CLASSE II - não-inertes: são aqueles que não se encaixam nas classes I e III, e que podem ser combustíveis, biodegradáveis ou solúveis em água;

CLASSE III - inertes: são aqueles que, ensaiados segundo o teste de solubilização da norma ABNT NBR 10006/1987, não apresentam qualquer de seus constituintes solubilizados em concentrações superiores aos padrões de potabilidade da água, executando-se os padrões de cor, turbidez, sabor e aspecto.

\section{5}

\section{Acondicionamento dos Resíduos Sólidos}

Acondicionamento é a fase na qual os resíduos sólidos são preparados de modo a serem mais facilmente manuseados nas etapas de coleta e de destinação final. Acondicionar significa dar ao lixo uma "embalagem" adequada, cujos tipos dependem de suas características e da forma de remoção, aumentando assim a segurança e a eficiência do serviço (Barros, 1995).

Segundo Fonseca (1999) os limites máximos aceitáveis de peso e de volume do lixo a ser coletado regularmente são estabelecidos por normas municipais que devem refletir as peculiaridades locais, orientando e educando a população, cuja colaboração é fundamental para a boa execução das atividades. O mau acondicionamento retarda o serviço e o encarece. Recipientes inadequados ou improvisados (pouco resistentes, mal fechados ou muito pesados), com materiais sem a devida proteção, aumentam o risco de acidentes de trabalho.

De acordo com o Manual de Saneamento e Proteção Ambiental para os Municípios (2002) os materiais agressivos ou perigosos devem ser acondicionados em separado do restante do lixo, para uma correta disposição. Os líquidos devem ser previamente retirados. Vidros quebrados e superfícies cortantes devem ser embrulhados em jornal. 


\section{6}

\section{Tratamento e Disposição Final dos Resíduos Sólidos}

Segundo o Manual de Saneamento e Proteção Ambiental para os Municípios (2002) O destino inevitável do lixo é um aterro. O que a comunidade, através de seus governantes, deve decidir é que proporção do lixo vai ser aterrada e de que forma este aterro vai ser feito, visto que os impactos ambientais, sociais e econômicos da disposição final do lixo são extremamente sérios.

Segundo a norma ABNT NBR 8419/1984, aterro sanitário é:

"uma técnica de disposição de resíduos sólidos urbanos no solo sem causar danos à saúde pública e à sua segurança, minimizando os impactos ambientais, método este que utiliza princípios de engenharia para confinar os resíduos sólidos à menor área possível e reduzilos ao menor volume permissível, cobrindo-os com uma camada de terra na conclusão de cada jornada de trabalho, ou a intervalos menores, se for necessário".

Esta técnica consiste basicamente da compactação dos resíduos no solo, dispondo-os em camadas que são periodicamente cobertas com terra ou outro material inerte, formando células, de modo a se ter uma alternância entre os resíduos e o material de cobertura.

A incineração é um processo de redução de peso (em até 70\%) e de volume (em até $90 \%$ ) do lixo através de combustão controlada, de 800 a $1000{ }^{\circ} \mathrm{C}$, visando a disposição final. O processo é realizado em fornos especiais, nos quais se pode garantir oxigênio para combustão, turbulência, tempos de permanência e temperaturas adequadas (Barros et al., 2003).

Segundo Alvez (2003) A reciclagem pode ser definida como sendo um conjunto de procedimentos que possibilita a recuperação e a reintrodução no ciclo produtivo de resíduos das atividades humanas como matérias-primas e/ou insumos de processos industriais, visando à produção de novos bens, idênticos ou similares aqueles que se originaram aos referidos resíduos. Em outras palavras, a reciclagem é a finalização de vários processos pelos quais passam os materiais que seriam descartados. Apenas após a coleta, separação e processamento, esses resíduos poderão ser reutilizados na composição de outros materiais. $\mathrm{O}$ acúmulo de dejetos e a exploração da natureza é uma constante preocupação. A reciclagem torna-se importante no que diz respeito à diminuição dessas duas práticas. No 
entanto existem algumas dificuldades, geradas pela falta de critérios de funcionamento, relacionadas à determinadas técnicas que podem ser observados em vários municípios, um exemplo deste mau funcionamento é a degradação causada por queima de resíduos (Alvez, 2003, p.22).

De acordo para Grippi (2006) o gerenciamento integrado do lixo municipal deve começar pelo conhecimento de todas as características desse lixo, pois vários fatores influenciam neste aspecto, tais como: Número de habitantes no município; Poder aquisitivo da população; Condições climáticas predominantes; Hábitos e costumes da população e o Nível educacional. Ainda deve levar em consideração as estimativas de lixo geradas per capta no município, visando planejamento adequado das atividades de coleta entre outros controles.

No Brasil, de cada 100 habitantes, 75 moram em cidades e o restante na zona rural. Esta migração crescente da zona rural para as grandes cidades desequilibra o gerenciamento do lixo, forçando as prefeituras a "correrem contra o tempo" para disponibilizar lugares para a colocação correta do lixo urbano (Grippi, 2006). O autor ainda relata quanto a disposição final do lixo urbano no Brasil, que $80 \%$ ocorre em lixão a céu aberto, $13 \%$ em aterros controlados; $5 \%$ em aterros sanitários; $1 \%$ usina de reciclagem; 0,9\% usina de compostagem e $0,1 \%$ usina de incineração.

Com o advento da Revolução Industrial e os altos investimentos em tecnologia, vários hábitos foram surgindo na população mundial, decretando um novo tipo de comportamento, que cada vez mais vem produzindo lixo de forma alarmante (Pereira Neto, 2007). Daí vem, então, a preocupação como destino final adequado dos resíduos sólidos urbanos, visando o bem-estar da população e diminuindo a utilização de recursos naturais. No Brasil, a maior parte dos municípios ainda não destina os seus resíduos de modo adequado, depositando-os, em sua maioria, em lixões e aterros controlados. Os resíduos devem receber destinação final sanitariamente apropriada, de forma a minimizar ao máximo os impactos ambientais. Mas deve-se ressaltar que a vida útil dos aterros não é infinita. 


\section{7 \\ Efeitos na saúde humana e no meio ambiente}

Os mais frequentes agentes físicos, químicos e biológicos presentes nos resíduos sólidos municipais e nos processos dos sistemas de seu gerenciamento, capazes de interferir na saúde humana e no meio ambiente são segundo (Ferreira, 1997).

\section{- Agentes físicos}

O odor emanado dos resíduos pode causar mal estar, cefaleias e náuseas em trabalhadores e pessoas que se encontrem proximamente a equipamentos de coleta ou de sistemas de manuseio, transporte e destinação final. Ruídos em excesso, durante as operações de gerenciamento dos resíduos, podem promover a perda parcial ou permanente da audição, cefaleia, tensão nervosa, estresse, hipertensão arterial. Um agente comum nas atividades com resíduos é a poeira, que pode ser responsável por desconforto e perda momentânea da visão, e por problemas respiratórios e pulmonares.

Em algumas circunstâncias, a vibração de equipamentos (na coleta, por exemplo) pode provocar lombalgias e dores no corpo, além de estresse. Responsáveis por ferimentos e cortes nos trabalhadores da limpeza urbana, os objetos perfurantes e cortantes são sempre apontados entre os principais agentes de riscos nos resíduos sólidos.

Nem sempre lembrada, a questão estética é bastante importante, uma vez que a visão desagradável dos resíduos pode causar desconforto e náusea.

\section{- Agentes químicos}

Nos resíduos sólidos municipais pode ser encontrada uma variedade muito grande de resíduos químicos, dentre os quais merecem destaque pela presença mais constante: pilhas e baterias; óleos e graxas; pesticidas/herbicidas; solventes; tintas; produtos de limpeza; cosméticos; remédios; aerossóis.

Uma significativa parcela destes resíduos é classificada como perigosa e pode ter efeitos deletérios à saúde humana e ao meio ambiente. Metais pesados 
como chumbo, cádmio e mercúrio, incorporam-se à cadeia biológica, têm efeito acumulativo e podem provocar diversas doenças como saturnismo e distúrbios no sistema nervoso, entre outras. Pesticidas e herbicidas têm elevada solubilidade em gorduras que, combinada com a solubilidade química em meio aquoso, pode levar à magnificação biológica e provocar intoxicações agudas no ser humano (são neurotóxicos), assim como efeitos crônicos (Kupchella \& Hyland, 1993).

\section{- Agentes biológicos}

Os agentes biológicos presentes nos resíduos sólidos podem ser responsáveis pela transmissão direta e indireta de doenças. Microorganismos patogênicos ocorrem nos resíduos sólidos municipais mediante a presença de lenços de papel, curativos, fraldas descartáveis, papel higiênico, absorventes, agulhas e seringas descartáveis e camisinhas, originados da população; dos resíduos de pequenas clínicas, farmácias e laboratórios e, na maioria dos casos, dos resíduos hospitalares, misturados aos resíduos domiciliares ( Ferreira, 1997).

Alguns agentes que podem ser ressaltados são: os agentes responsáveis por doenças do trato intestinal (Ascaris lumbricoides; Entamoeba coli; Schistosoma mansoni); o vírus causador da hepatite (principalmente do tipo B), pela sua capacidade de resistir em meio adverso; e o vírus causador da Síndrome da Imuno Deficiência Adquirida (AIDS), mais pela comoção social que desperta do que pelo risco associado aos resíduos, já que apresenta baixíssima resistência em condições adversas. Além desses, devem também ser referidos os microorganismos responsáveis por dermatites e por doenças sexualmente transmissíveis (DSTs) tais como a sífilis e a gonorreia.

A transmissão indireta se dá pelos vetores que encontram nos resíduos, condições adequadas de sobrevivência e proliferação.

Entre os resíduos com presença de microorganismos, merecem ainda ser mencionados os resíduos infecciosos dos serviços de saúde que, pela falta de uma melhor compreensão dos modos de transmissão dos agentes associados a doenças infecciosas, têm sido alvo de receios exagerados da população em geral (Ferreira, 1997). Contudo, isto não deve servir de justificativa para que as instituições de 
saúde não estabeleçam procedimentos gerenciais que reduzam os riscos associados a tais resíduos (principalmente dos perfurocortantes) com a sua desinfecção ou esterilização.

\section{8}

\section{O PVC atóxico}

O PVC ocupa lugar de destaque entre os materiais plásticos presentes no nosso cotidiano. Ele tem papel importante na indústria e na sociedade e tem as mais diversas aplicações, desde produtos médico-hospitalares e embalagens para alimentos até peças de alta tecnologia, como as usadas em equipamentos espaciais, passando por produtos aplicados à habitação e saneamento básico, dentre diversos outros setores. A cada instante, onde encontramos conforto e modernidade, encontramos o PVC. Sua presença tornou-se tão familiar que nem mais a notamos.

O PVC é atóxico, leve, sólido, resistente, impermeável, estável e não propaga chamas. Tem qualidades que o tornam adaptável a múltiplos usos, da garrafa ao painel do carro, sendo o único plástico utilizado para a fabricação de bolsas de sangue. Sem dúvida, ele é parte integrante do nosso dia-a-dia.

O PVC pode ser rígido ou flexível, opaco ou transparente, brilhante ou fosco, colorido ou não. Estas características são obtidas com a utilização de plastificantes, estabilizantes térmicos, pigmentos, entre outros aditivos, usados na formulação do PVC. Após formulado obtém-se os compostos de PVC que são utilizados na fabricação de uma série de produtos, tais como:

- Produtos médico-hospitalares: embalagens para medicamentos, bolsas de sangue (sendo o material que melhor conserva o sangue), tubos para transfusão e hemodiálise, artigos cirúrgicos, além de pisos de salas onde é indispensável o alto índice de higiene;

- Janelas: oferecem excelente resistência às mudanças de clima e à passagem dos anos, mesmo em ambientes corrosivos (por exemplo, beira-mar), em áreas rurais ou urbanas;

- Pisos e revestimentos de paredes: peças decorativas, resistentes e facilmente laváveis; 
- Brinquedos e artigos infláveis: bolas, boias, colchões e barcos, etc.

- Artigos escolares: facilmente moldados, têm grade variedade de aspectos (cor, brilho, transparência) embaixo custo;

- Embalagens: usadas para acondicionar alimentos, protegendo-os contra umidade e bactérias. Estas embalagens são impermeáveis ao oxigênio e ao vapor, dispensando, assim, o uso de conservantes, preservando o aroma;

- Tecidos espalmados decorativos e técnicos: usados principalmente para móveis, vestuários, malas e bolsas;

- Garrafas para água mineral: leves e transparentes;

- Estruturas de computadores: assim como peças técnicas destinadas à indústria eletrônica;

-Automóveis: aplicado a revestimento de interiores devido à sua facilidade de moldagem e de manutenção;

- Tubos e conexões: utilizados na canalização de água (potável ou não) e esgotos, pois são resistentes e facilmente transportados e manipulados graças ao seu baixo peso. No caso da água potável evita contaminações externas e previne perdas por vazamento, devido à fácil e eficiente soldagem entre os tubos e as conexões. Também são muito utilizados em sistemas de irrigação, de redes subterrâneas e de superfícies a tubulações e filtros para poços profundos e minas, além de redes de drenagem agrícolas e de estradas;

-Mangueiras: são flexíveis, transparentes e coloridas;

- Laminados impermeáveis: utilizados em piscinas, túneis, tetos, etc e também para a impermeabilização de aterros sanitários, protegendo o solo e lençóis freáticos;

- Frascos para acondicionar cosméticos e produtos domésticos: por sua impermeabilidade e resistência a produtos químicos e ótima relação custo benefícios na hora da troca de moldes, além de facilitar o design;

- Móveis de jardim: têm grande resistência às variações climáticas e são de fácil manutenção

- Materiais eróticos: Próteses de formatos variados de PVC. 
É justamente o descarte de materiais eróticos, em especial próteses de PVC, o foco da pesquisa. É um material atóxicomas contaminado por agentes biológicos (Classe I). 


\section{3. \\ Ambiente e Saúde: os achados da pesquisa}

Para responder às questões de fundo desta pesquisa qualitativa foram realizadas entrevistas semi estruturadas. De acordo com Ludke e André (1986) nas entrevistas não totalmente estruturadas, onde não há imposição de uma ordem rígida de questões, o entrevistado discorre sobre o tema proposto com base nas informações que ele detém e que no fundo são a verdadeira razão da entrevista. $\mathrm{Na}$ medida em que houver um clima de estimulo e de aceitação mutua, as informações fluem de maneira notável.

Foram selecionados três grupos de informantes: profissionais da indústria, lojistas e consumidores.

Os profissionais da indústria e os lojistas foram recrutados com base em pesquisa preliminar feita na lista pessoal da pesquisadora nas cidades do Rio de Janeiro, São Paulo e Rio Grande do Sul.

As entrevistas foram realizadas, em sua maioria, nos locais de trabalho dos entrevistados, fábricas e lojas. Alguns entrevistados eram vendedores, fornecedores e outros proprietários de sexshop.

Os consumidores, a maioria mulheres, foram recrutadas, inicialmente, a partir da rede social da pesquisadora, que entrevistou amigas, conhecidas e clientes que eram consumidoras de produtos eróticos. Como pré-requisitos, pediase apenas que fossem consumidores de produtos eróticos. Não havia restrição de idade ou classe social, o que enriqueceu ainda mais as propriedades exploratórias desta pesquisa, gerando panorama amplo que pode servir a pesquisas futuras, de foco mais restrito sobre determinados estratos.

Além de poder ser tratado como assunto confidencial, consumo erótico pode constituir, também, o que Renzetti e Lee (1993, p.5) definem como "tópico sensível”. Para esses autores, um tópico sensível é aquele que apresenta algum tipo de ameaça aos envolvidos, o que torna problemática, para o pesquisador ou para o pesquisado, a coleta, aposse ou a disseminação de dados de pesquisa. Para Sayre (2006), o tópico sensível pode apresentar a ameaça de sanções sociais ou 
políticas. Por esse motivo, além das dificuldades inerentes à entrevista em si, o próprio recrutamento de informantes pode ser mais complicado quando o tema a ser investigado é considerado sensível (GER E SANDIKCI, 2006).

As entrevistas versaram basicamente em torno do descarte das próteses e da responsabilidade sócio ambiental.

\section{1}

\section{O Descarte}

Segundo Walther (2012), a etapa do descarte dentro do ciclo do consumo pode revelar negociações de papel social e transições de identidade.

Como se desfazer de uma prótese velha ou quebrada? Por motivos emocionais e por motivos práticos, o processo de descarte dos produtos eróticos pode vir a ser mais complicado do que de qualquer outro produto, varias consumidoras contaram ter saído de carro para jogar as próteses em lixeiras publicas longe de casa por vergonha de serem descobertas por vizinhos. Dos entrevistados que formavam um casal de consumidores se preocupou, não somente em ser discreto na hora de descartar os produtos, e sim de picotar e destruir cada um deles, para que o mesmo não pudesse ser usado por outras pessoas. Em seu relato palavras como "enterro" "cadáver" "saco preto" e "desovar" são presentes. Como se viu, o descarte de próteses é mais complicado, feito em sigilo e às vezes com ajuda de pessoas de confiança.

O fabricante de prótese de São Paulo narrou seu problema com o descarte das próteses. Os vizinhos descobriram que as próteses com algum defeito na fabricação ou as próteses de teste eram jogadas em lixo comum, então à noite os vizinhos da região iam até o lixo da fabrica e pegavam essas próteses defeituosas. A solução para esse problema foi armazenar uma quantidade significante dessas próteses dentro da fabrica e descartar direto em um lixão da cidade.

O fabricante do Rio grande do sul nunca enfrentou nenhum problema com o descarte de suas próteses que são descartadas junto com o restante dos resíduos da fabrica.

Os lojistas de uma maneira geral juntam todas as próteses não usadas e com 
defeito de fabrica para enviar ao fabricante em troca de produtos sem defeito. Já as próteses usadas pelos clientes que apresentaram defeito após o uso vão para o lixo.

\section{2}

\section{A Responsabilidade Socioambiental}

Foi perguntado aos clientes, fabricantes e lojistas se em algum momento eles já haviam se preocupado com o descarte desse tipo de material usado no meio ambiente.

Todos os clientes se mostram surpresos e interessados com o questionamento, ficaram reflexivos sobre o assunto, e levantaram vários outros questionamentos como: Qual seria o descarte correto da prótese? A camisinha poderia ser descartada de alguma outra maneira? O fabricante não deveria se responsabilizar por isso?

Foi feita a mesma pergunta para os fabricantes, o de São Paulo diz nunca ter pensando sobre isso e que a produção de resíduo dele é muito pequena para se preocupar com isso.

O fabricante do sul diz que se preocupa com esse tipo de descarte, que tenta aproveitar toda a parte eletrônica, a fiação, as baterias, e que tenta de maneira geral arrumar uma destinação interessante para as próteses com defeito de fabrica, como doar para peças de teatro.

Já os lojistas tem uma preocupação maior com as próteses utilizadas pelos clientes que retornam para eles. Usam luvas para manipular o produto, mas não têm nenhum cuidado ao descartar o material contaminado. 


\section{4. \\ Considerações finais}

Doar as próteses é praticamente impossível, além de ser um objeto pessoal que gira em torno de um tabu. É um material usado e contaminado e por isso as próteses eletrônicas ou são esquecidas em alguma gaveta ou são descartadas em lixo comum.

Mesmo sendo possível reciclar toda parte eletrônica do produto como é feito em algumas lojas em outros países da Europa, que é encaminhado para reciclagem e, de quebra, o/a proprietário do artigo ganha desconto de $50 \%$ em um novo produto, como prêmio por sua consciência ecológica, não foi o que levantamos nas entrevistas.

A iniciativa Europeia aumenta as vendas das próteses e é uma ótima alternativa de descarte consciente. Todo o material eletrônico é reciclado pelo fabricante e a parte de PVC é descartada de maneira adequada.

As empresas brasileiras de mercado erótico poderiam oferecer a mesma opção que é feita em alguns países da Europa, sendo vantagem para todos da cadeia de consumo.

Para Minc (1997:108)

"Os programas aplicados de ecodesenvolvimento sugerem a reformulação do antigo lema ecológico: Pensar globalmente, agir localmente. Devemos pensar global e localmente e agir de forma coordenada local e globalmente, conectados nos avanços mundiais e integrando as experiências locais com a democratização radical e a despoluição do poder político"

Além do desconto, o lojista ofereceria aos consumidores um serviço gratuito de descarte de vibradores velhos ou danificados, desejo manifestado de maneira explicita pelos os entrevistados da presente pesquisa. Viu-se que o descarte de próteses pode ser muito problemático, porque além de abrigar memórias a prótese é presença indiscreta no lixo domestico segundo Walther (2012).

Ficou claro que durante as entrevistas que principalmente os clientes que são os consumidores finais nunca tinham pensado sobre o assunto de forma sócio ambiental e em todos os problemas que o descarte inadequado desse material pode 
acarretar.

Segundo Guattari (2006, p.14) "é nesse contexto de ruptura, de descentramento, de multiplicação dos antagonismos e de processos de singularização que surgem as novas problemáticas ecológicas”. 


\section{5. \\ Referências bibliográficas}

ACCURIO, G.; ROSSIN, A.; TEIXEIRA, P. F. \& ZEPEDA, F., 1998. Diagnóstico de La Situación del Manejo de Residuos Sólidos Municipales en América Latina y El Caribe. Organización Panamericana de la Salud/Organización Mundial de La Salud, Serie Ambiental noํㅜㄹ. Washington, DC: Organización Panamericana de la Salud/Organización Mundial de La Salud, 1999 .

ALVEZ, R. O. Análise da viabilidade econômica da implantação de uma indústria de reciclagem de embalagens e PET na região de Ouro Preto. Monografia de Graduação em Engenharia de Produção. Universidade Federal de Ouro Preto, dez, 2003. Disponível: http://www.ichs.ufop.br/cadernosdehistoria/download/CadernosDeHistoria-0414.pdf.

ANJOS, L. A.; BARROS, A. A.; FERREIRA, J. A.; OLIVEIRA, T. C. E.; SEVERINO, K. C.; SILVA, M. O. \& WAISSMANN, W. Gasto Energético e Carga Fisiológica de Trabalho em Coletores de Lixo Domiciliar no Rio de Janeiro: Um Estudo Piloto. Relatório de Pesquisa. Rio de Janeiro: Centro de Estudos da Saúde do Trabalhador e Ecologia Humana, Escola Nacional de Saúde Pública, Fundação Oswaldo Cruz, 1995.

ANJOS, L. A. \& FERREIRA, J. A. . A avaliação da carga fisiológica de trabalho na legislação brasileira deve ser revista! $O$ caso da coleta de lixo domiciliar. Cadernos de Saúde Pública, 16:785-790, 2000.

ATYEL, S. O. Gestão de Resíduos Sólidos: O caso das Lâmpadas Fluorescentes (dissertação). Porto $\quad$ Alegre. 111p. Disponível: http://www.sober.org.br/palestra/6/832.pdf.

BARROS, R. T. V. et al. Manual de saneamento e proteção ambiental para os municípios. Escola de Engenharia da UFMG, Belo Horizonte - MG, 2003, 221p. Disponível: http://rdigital.univille.rctsc.br/index.php/RSA/article/viewFile/91/146. 
Saneamento. Belo Horizonte. Escola de Engenharia da UFMG, 1995. (Manual de Saneamento e Proteção Ambiental para os Municípios), 1995.

BRASIL. Parâmetros curriculares nacionais: meio ambiente e saúde. Brasília:Secretaria de Educação Fundamental, 1997.

BRUSCHI D.M Município e meio ambiente. Belo Horizonte: FEAM, 2002. .; (Manual de saneamento e proteção ambiental para os municípios. Disponível: http://www.em.ufop.br/ceamb/petamb/cariboost_files/manual_20de_20saneament o_municipios_feam_2002.pdf.

CAMPBELL, D. J. V., 1999. Institutional development for waste management in developing countries. Waste Management \& Research, 17:1-3.

CANTANHEDE, A., 1997. Experiences from the Pan- American Centre of Sanitary Engineering \& Environmental Sciences - Difficulties and possibilities. In: Latin American-Swedish Seminar on Solid Waste Management, Proceedings, pp. 163-168. Rio de Janeiro: Associação Brasileira de Engenharia Sanitária e Ambiental/Lund University.

CETESB (Companhia de Tecnologia de Saneamento Ambiental), 1998. Inventário Estadual de Resíduos Sólidos Domiciliares. São Paulo: CETESB.

CETESB, Aterro Sanitário. Conselho Nacional de Desenvolvimento Urbano. São Paulo, 1979.34p.il. Disponível: http://www.bvsde.paho.org/bvsaidis/resisoli/brasil/iii-004.pdf.

CHOR, D., 1999. Saúde Pública e mudanças de comportamento: Uma questão contemporânea. Cadernos de Saúde Pública, 15:423-425.

COLOMBI, A.; BASILICO, S. \& FOÁ, V., 1995. Riesgos para la salud de los trabajadores asignados a las instalaciones de tratamiento y eliminacion de los desechos. Acta Toxicologica, 3:28-37.

DIAZ, L. F.; SAVAGE, G. M. \& EGGERTH, L. L., 1997. Managing solid wastes in developing countries. Wastes Management, 10:43-45. 
DOLL, R., 1992. Health and the environment in the 1990s. American Journal of Public Health, 82:933-940.

FERREIRA, J. A., 1997. Lixo Hospitalar e Domiciliar: Semelhanças e Diferenças - Estudo de Caso no Município do Rio de Janeiro. Tese de Doutorado, Rio de Janeiro: Escola Nacional de Saúde Pública, Fundação Oswaldo Cruz.

FRIGOTTO, G.A. A produtividade na escola improdutiva. São Paulo: Cortez, 2001.

FIGUEIREDO; P. J. M. A sociedade do lixo: os resíduos, a questão energética e a crise ambiental. 2a Edição. UNIMEP: Piracicaba, 1994. Disponível: http://www.ichs.ufop.br/cadernosdehistoria/download/CadernosDeHistoria-0414.pdf.

FONSECA, Iniciação ao Estudo dos Resíduos Sólidos e da Limpeza Urbana: A União. 1999.122p.

FRANCO, T. R. Coleta seletiva de lixo domiciliar: estudos para implantação. Monografia (Bacharelado) - Instituto de Geografia, Universidade Federal de Uberlândia, Uberlândia, $2000 . \quad$ Disponível: http://www.ichs.ufop.br/cadernosdehistoria/download/CadernosDeHistoria-0414.pdf.

GALVÃO JR., A. C. Aspectos operacionais relacionados com usinas de reciclagem e compostagem de resíduos sólidos domiciliares no Brasil. São Carlos, 1994. Dissertação (Mestrado) - Escola de Engenharia de São Carlos, Universidade de São Paulo. http://www.bvsde.paho.org/bvsaidis/resisoli/brasil/iii-004.pdf.

GER,G. Doing Research on Sensitive Topics: Studying Covered Turkish Human. In BELK,R. Handbook of Qualitative Research Methods in Marketing. Glos: Edward Elgar Publishing, 2006.

GRIPPI, S. Lixo, reciclagem e sua história. Guia para as prefeituras brasileiras. $\begin{array}{llll}\text { Rio de Janeiro: } & \text { Interciência, }\end{array}$ 
GUATTARI, F. As Três Ecologias. São Paulo: Papirus, 1990.

INSTITUTO BRASILEIRO DE GEOGRAFIA E ESTATISTICA (IBGE) 2000.

Disponível: http://www.ibam.org.br/publique/media/Boletim1a.pdf.

INSTITUTO BRASILEIRO DE GEOGRAFIA E ESTATISTICA (IBGE>. Censo populacional no país. 2005.2 Disponível:

http://www.sober.org.br/palestra/6/832.pdf.

JARDIM, Niza Silva et al. Lixo Municipal: Manual de Gerenciamento integrado. São Paulo: IPT: CEMPRE, 1995.

JOHN, V. M; ANGUlO, S.C; AGOPYAN, V. Sobre a necessidade de metodologia de pesquisa e desenvolvimento para reciclagem. $\mathrm{PCC}-$ Departamento Engenharia de Construção Civil da Escola Politécnica. EP USP. Disponível:

http://www.ichs.ufop.br/cadernosdehistoria/download/CadernosDeHistoria-0414.pdf.

MINC, C. Ecologia e cidadania. 2a ed. São Paulo: Moderna, 1998. Disponível: http://www.ichs.ufop.br/cadernosdehistoria/download/CadernosDeHistoria-0414.pdf.

JOHNSTON, B. R., 1995. Human rights and the environment. Human Ecology, 23:111-123.

KUPCHELLA, C. D. \& HYLAND, M.C., 1993. Environmental Science - Living Within the System of Nature. London: Prentice-Hall International.

LEBEL, J. Salud:um enfoque ecossistêmico. Bogota: Alfaomega, 2005.

LEFF, E. Saber ambiental. Petrópolis:Vozes,2001

LEITE, V. D. \& LOPES, W. S., 2000. Avaliação dos Aspectos Sociais, Econômicos e Ambientais Causados pelo Lixão da Cidade de Campina Grande. In: IX Simpósio Luso-Brasileiro de Engenharia Sanitária e Ambiental, Anais, CD- 
ROM IV. Porto Seguro: Associação Brasileira de Engenharia Sanitária e Ambiental.

LIMA, M. C.; DAMIÃO, J. J.; WERNERSBACH, L. \& ANJOS, L. A., 1997. Características nutricionais e fatores de risco para doenças cardiovasculares em coletores de lixo domiciliar no Município do Rio de Janeiro. In: $1^{\stackrel{o}{ }}$ Congresso Brasileiro de Atividade Física e Saúde e $7^{\circ}$ Simpósio de Pesquisa em Educação Física, Anais, p. 122. Florianópolis: Universidade Federal de Santa Catarina.

LÜDKE, M e ANDRE, M. Pesquisa em educação: abordagens qualitativas. São Paulo: EPU, 1986.

MACHADO, C. \& PRATA FILHO, D. A., 1999. Gestão de Resíduos Sólidos Urbanos em Niterói. In: $20^{\circ}$ Congresso Brasileiro de Engenharia Sanitária e Ambiental, Anais, CD-ROM III. Rio de Janeiro: Associação Brasileira de Engenharia Sanitária e Ambiental.

MAGLIO, I. C., 2000. Gestão Ambiental dos Resíduos Sólidos - O Papel dos Municípios. In: 9ํㅗำ Simpósio Luso-Brasileiro de Engenharia Sanitária e Ambiental, Anais, CD-ROM VI. Porto Seguro: Associação Brasileira de Engenharia Sanitária e Ambiental.

MATTOS, U. A. O. 1992. Introdução ao Estudo da Questão Saúde e Trabalho. Rio de Janeiro: Centro de Estudos da Saúde do Trabalhador e Ecologia Humana, Escola Nacional de Saúde Pública, Fundação Oswaldo Cruz.

MALMROS, P.; SIGSGAARD, T. \& BACH, B., 1992. Occupational Health Problems due to Garbage Sorting. Waste Management \& Research, 10:227-234.

MENDES, R., 1988. O Impacto dos efeitos da ocupação sobre a saúde dos trabalhadores. Revista de Saúde Pública, 22:311-326.

MINAYO, M.C. Saúde e ambiente: uma relação necessária. In CAMPOS, G,W.S. Tratado de saúde coletiva. Rio de Janeiro: Ed. Fiocruz, 2009.

MINC, C. Ecologia e cidadania. São Paulo: Moderna, 1997 
PEREIRA NETO. .T. Manual de compostagem: processo de baixo custo. Viçosa, MG: UFV, 2007.

PORTO, M. F. S., 1998. Saúde, ambiente e desenvolvimento: Reflexões sobre a experiência da COPASAD - Conferência Panamericana de Saúde e Ambiente no Contexto de Desenvolvimento Sustentável. Ciência \& Saúde Coletiva, 3:33-46.

PRESIDÊNCIA DA CASA CIVIL. Subchefia para Assuntos Jurídicos. LEI N ${ }^{\circ}$ 12.305, DE 2 DE AGOSTO DE 2010. Disponível: <http://www.planalto.gov.br/ccivil_03/_ato2007-2010/2010/lei/112305.htm>;

REINHARDT, P. A.; GORDON, J. \& ALVARADO, C. J., 1996. Medical waste management. In: Hospital Epidemiology and Infection Control (C. G. MayHall, ed.), pp. 1099-1108, $1^{\text {st }}$ Ed., Baltimore: Williams \& Wilkins.

RENZETTI, C.M e LEE,R.M. Researching Sensitive topics. Newbury Park, CA: Sage, 1993.

ROBAZZI, M. L. C.; MORIYA, T. M.; FÁVERO, M. \& PINTO, P. H. D., 1992. Algumas considerações sobre o trabalho dos coletores de lixo. Revista Brasileira de Saúde Ocupacional, 20:34-40.

RUBERG, C. \& PHILIPPI Jr., A., 1999. O Gerenciamento de Resíduos Sólidos Domiciliares: Problemas e Soluções - Um Estudo de Caso. In: $20^{\circ}$ Congresso Brasileiro de Engenharia Sanitária e Ambiental, Anais, CD-ROM III. Rio de Janeiro: Associação Brasileira de Engenharia Sanitária e Ambiental.

RUTALA, W. A. \& MAYHALL, C. G., 1992. Medical waste. Infection Control and Hospital Epidemiology, 13:38-48.

SAVRE, S. Using video- elicitation to Research Sensitive Topics:Understanding the Purchase Process Following Natural Disaster. In BELK,R. Handbook of Qualitative Research Methods in Marketing. Glos: Edward Elgar Publishing, 2006.

SCHRAMM, F. R., 1992. Ecologia, ética e saúde: O principio da responsabilidade. In: Saúde, Ambiente e Desenvolvimento (M. C. Leal; P. C. 
Sabroza; R. H. Rodrigues \& P. M. Buss, orgs.), pp. 233-255, vol. 2, São Paulo: Hucitec/Rio de Janeiro: Abrasco. Disponível: http://www.bvsde.paho.org/bvsacd/cd48/v11n2a14.pdf.

SIVIERI, L. H., 1995. Saúde no trabalho e mapeamento de riscos. In: Saúde, Meio Ambiente e Condições de Trabalho - Conteúdos Básicos para uma Ação Sindical. São Paulo: Central Única dos Trabalhadores/Fundação Jorge Duprat Figueiredo de Segurança e Medicina no Trabalho.

SOUZA,D. D. Coprocessamento. Revista Meio Ambiente Industrial, março/abril de 2012, pág., 76 a 82

UNITED NATIONS, 1992. Drafts - Agenda 21 - Rio Declaration - Forest Principles. Rio de Janeiro: United Nations.

VELloso, M. P., 1995. Processo de Trabalho da Coleta de Lixo Domiciliar da Cidade do Rio de Janeiro: Percepção e Vivência dos Trabalhadores. Dissertação de Mestrado, Rio de Janeiro: Escola Nacional de Saúde Pública, Fundação Oswaldo Cruz.

VELLOSO, M. P.; SANTOS, E. M. \& ANJOS, L. A., 1997. Processo de trabalho e acidentes de trabalho em coletores de lixo domiciliar na cidade do Rio de Janeiro, Brasil. Cadernos de Saúde Pública, 13: 693-700

VELlOSO, M. P.; VALlADARES, J. C. \& SANTOS, E. M., 1998. A coleta de lixo domiciliar na Cidade do Rio de Janeiro: Um estudo de caso baseado na percepção do trabalhador. Ciência \& Saúde Coletiva, 3:143-150.

WALTHER, L.C.C.L. Consumo erótico feminino e cultura material. Tese de Doutorado. Rio de Janeiro: UFRJ, 2012.

ZEPEDA, F., 1995. El Manejo de Residuos Solidos Municipales En America Latina y El Caribe. Washington, DC: Organización Panamericana de la Salud 